\title{
Estratégias de Aquisição e Disseminação de Conhecimento para Apoiar o Desenvolvimento de Software com o RUP
}

\author{
Rodrigo Fernandes de Oliveira - rodrigo@improveit.com.br \\ Ana Regina C. da Rocha - darocha@centroin.com.br \\ Guilherme Horta Travassos - ght@cos.ufrj.br \\ COPPE/UFRJ - Programa de Engenharia de Sistemas e Computação
}

\begin{abstract}
Resumo
As empresas vêm demonstrando ao longo dos últimos anos um grande interesse no desenvolvimento OO. Nesse sentido, muitas delas já adotaram o RUP como base para seu processo de desenvolvimento. Por ser um framework para processo, diversas variáveis podem afetar sua adaptação, execução e gerência para um projeto. Ter conhecimento sobre essas variáveis e os impactos causados por elas no projeto é fundamental para melhoria contínua do processo. Através da definição de uma estratégia para adquirir conhecimentos, tais como pontos fortes e fracos aprendidos ao longo do projeto, pretende-se atacar com mais objetividade os processos mais deficientes (pontos fracos) e incentivar que os pontos fortes continuem sendo aplicados em projetos futuros. Um estudo de caso aplicando a estratégia de aquisição de conhecimento em um projeto que utiliza um processo baseado no RUP é apresentado. Além disso, uma estratégia para disseminação de conhecimento é descrita. Essa estratégia está fundamentada na construção de planos de ação elaborados com base nas necessidades da equipe.
\end{abstract}

Palavras-Chave: Aquisição e Disseminação de Conhecimento, Melhoria de Processo, RUP

\begin{abstract}
Enterprises have demonstrated along the years their interest in object-oriented based development. As a consequence, some of them have adopted the RUP as the basis for their software development process. RUP represents a process framework. Therefore, several variables can affect its adaptation, execution and management when applied to a project. At this context, to have knowledge about these variables value and be able to identify their impact on the project is basic for continuous process improvement. By defining a strategy to acquire process knowledge, such as project's strong and weak points, we intend to deal more objectively with most deficient processes (weak points) and stimulate strong points continue to be applied in future projects. A case study applying such knowledge acquisition strategy on a RUP based project is discussed. Moreover, a strategy for knowledge dissemination is also described. This dissemination strategy is based on the construction of action plans elaborated according the team needs.
\end{abstract}

Keywords: Knowledge Acquisition and Dissemination, Process Improvement, RUP

\section{Introdução}

Com o objetivo de melhorar o seu processo de desenvolvimento, as empresas vêm demonstrando ao longo dos últimos anos um grande interesse no desenvolvimento orientado a objetos (OO). Em se tratando de processos de desenvolvimento para utilização da OO, diversas empresas já adotaram o RUP, tais como IBM, Microsoft e HP [1]. O RUP apresenta diversas atividades e artefatos que permitem a aplicação efetiva da UML ao longo do processo. Além disso, conceitos como fases e iterações oferecem ao gerente do projeto mecanismos e objetivos bem definidos para gerenciar o processo.

Embora o RUP apresente algumas constantes (tais como as fases e os processos), diversas variáveis podem afetar sua adaptação, execução e gerência para um projeto. Para cada projeto podemos ter um processo diferente. Cada cliente possui necessidades diferentes. Cada equipe

tem seus pontos fortes e fracos. É nesse momento que a experiência faz a diferença. É nesse momento que o gerente do projeto deve buscar pessoas com conhecimento no processo [2]. 
Gerenciar conhecimentos adquiridos em projetos anteriores e torná-los reutilizáveis em projetos futuros é de vital importância para qualquer organização [3,4], principalmente para organizações produtoras de software, pois o processo é bastante complexo e inovador.

Desta forma, uma evolução na norma ISO/IEC 12207 já traz o processo de Gerência de conhecimento como um processo inerente ao processo de gerência [5]. Segundo a mesma, o processo de gerência do conhecimento tem como objetivo assegurar que o conhecimento individual, informações e perfis sejam coletados, compartilhados, reutilizados e melhorados através da organização. Como resultado da execução do processo de gerência de conhecimento, temos:

- estabelecimento e manutenção da infra-estrutura para compartilhar informações e domínios comuns através da organização;

- aproveitamento dos bens intelectuais da organização através dos mecanismos estabelecidos;

- disponibilidade e compartilhamento do conhecimento pela organização; e

- seleção de estratégias apropriadas de gerência do conhecimento pela organização.

Esse artigo tem como objetivo apresentar estratégias de aquisição e disseminação de conhecimento para apoiar o desenvolvimento de software com o RUP, proporcionando um ambiente de aprendizado e melhoria contínua. Através da definição de uma estratégia para reter conhecimentos, tais como pontos fortes e fracos aprendidos ao longo do projeto, pretende-se atacar com mais objetividade os processos mais deficientes (pontos fracos) e incentivar que os pontos fortes continuem sendo aplicados em projetos futuros. Um estudo de caso aplicando a estratégia de aquisição de conhecimento em um projeto RUP será apresentado. Além disso, uma estratégia para disseminação de conhecimento será descrita. Essa estratégia está fundamentada na construção de planos de ação elaborados com base nas necessidades da equipe, tais como histórico de pontos fracos da equipe, características do projeto e também conhecimentos aprendidos em outros projetos realizados por outras equipes.

\section{Estratégia de Aquisição de Conhecimento}

É através da aplicação de uma estratégia de aquisição de conhecimento que a organização evita que alguns dos conhecimentos adquiridos nos projetos sejam perdidos [6]. Diversas experiências são vivenciadas ao longo de um projeto, de forma que cabe à organização traçar meios de capturar esses conhecimentos sem trazer problemas ao projeto em andamento.

De acordo com [7], algumas estratégias para aquisição de conhecimento falham porque seu processo de aplicação é muito informal e, também, porque os conhecimentos adquiridos não são vinculados aos processos de negócio. Além disso, quando as estratégias são centradas apenas em tecnologia (como um banco de dados, por exemplo) e não no comportamento, na cultura e em mudanças organizacionais, os resultados esperados nunca se materializam.

Sendo assim, é importante definir de forma clara quais conhecimentos são de interesse, como esses conhecimentos serão adquiridos e em que momento. Também é importante saber o que se deseja fazer com esses conhecimentos, quais são as metas da organização com a estratégia e como essas metas serão alcançadas.

\section{Revisões de Projeto}

Embora saibamos da importância que é reter os conhecimentos adquiridos ao longo dos projetos, é muito difícil colocar em prática esse objetivo sem que haja uma estratégia sobre 
como atingi-lo. Algumas experiências sobre a utilização de Revisões de Projeto (RP) demonstram ser essa uma estratégia muito boa para retenção de conhecimentos [8]. Essa estratégia tem como objetivo principal identificar os sintomas e as causas de sucesso ou fracasso ao longo do projeto, através de reuniões onde os participantes debatem sobre os pontos fortes e fracos ocorridos. RP podem ser feitas ao término do projeto (onde também são conhecidas como Revisões Postmortem), quando o projeto atinge um marco importante ou sempre que a organização julgar relevante.

Um ambiente de confiança mútua deve ser proporcionado no sentido de permitir que os membros do projeto se sintam motivados a dar informações sobre os eventos e fatores que afetaram o mesmo. É preciso que haja um clima amistoso entre os membros do projeto para que se possa atingir os reais objetivos das RP.

Como resultado das RP, pontos fracos (sintomas e causas de fracasso) e pontos fortes (sintomas e causas de sucesso) são então capturados e analisados, passando a fazer parte do repositório de conhecimentos da organização.

Para fazer com que a aplicação das RP se torne parte da cultura organizacional, uma série de considerações deve ser levada em conta de forma a facilitar a compreensão e aumentar a receptividade das mesmas [9]:

- Tarefas e papéis devem estar bem documentados e acessíveis por todos

- Estabelecer um canal de comunicação seguro entre os indivíduos

- Transparecer aos participantes a importância das RP

- Responder de comum senso que os resultados obtidos são para efeito de documentação apenas

- Ser capaz de balancear coerentemente os custos envolvidos na aplicação das RP com o $\mathrm{ROI}^{1}$ obtido

Sendo assim, é importante que essas considerações venham a guiar a definição de um processo para aplicação das RP. Pode-se encontrar na literatura alguns exemplos desses processos. Alguns mais complexos, e que se aplicam apenas a projetos maiores [9], enquanto outros mais simples, para projetos de pequeno e médio porte [8]. Alguns deles com foco na captura de causas de sucesso [10] e outros na captura de causas de fracasso [9]. A abordagem utilizada nesse trabalho tem como base as propostas de [8] e [9]. Essa abordagem considera que a aplicação das RP envolve três fases principais, a saber: fase de preparação, fase de coleta de dados e, por último, a fase de análise. Cada uma das fases será descritas em detalhes nas seções seguintes.

\section{Preparação}

A fase de preparação tem como objetivo prover o grupo responsável pela execução das RP de informações sobre o projeto. Documentos que ofereçam uma visão do projeto, o processo utilizado, o Plano do Projeto, entre outros, podem ser fornecidos. O ideal é que pessoas que não participaram do projeto conduzam as RP [8], pois elas tendem a ser mais objetivas e neutras. Essas pessoas podem ser da própria organização ou externas.

Objetivos também podem ser definidos para as RP, como por exemplo "Capturar conhecimentos para melhorar o processo de análise e projeto", que visam aprimorar um determinado processo. Também é possível que o objetivo seja capturar quaisquer tipos de conhecimentos. Nesse caso, pode ser importante utilizar um questionário, na fase de coleta de dados, para determinar quais são os assuntos (ou processos) a serem priorizados.

\footnotetext{
${ }^{1}$ Return Of Investment, ou retorno do investimento
} 


\section{Coleta de Dados}

Depois de definidos os objetivos das RP, pode ser preciso coletar dados para que seja possível identificar quais tópicos são mais importantes de serem discutidos e analisados. Tanto dados subjetivos quanto objetivos podem ser utilizados. Uma forma de coletar dados subjetivos, simples de ser utilizada, é através de questionários.

Utilizar questionários para capturar informações dos participantes do projeto é uma solução simples e de baixo custo, principalmente quando são disponibilizados através de meio eletrônico [9]. Os resultados poderão ser utilizados de várias maneiras:

- para guiar as RP, definindo os tópicos mais importantes a serem discutidos

- provendo dados quantitativos a serem confrontados com questionários anteriores, de forma a avaliar o grau de melhoria dos processos da organização

- como argumento de convencimento de outras pessoas da organização, sendo utilizado para demonstrar áreas problemáticas ou melhorias alcançadas depois de determinada ação.

Dados objetivos também devem ser coletados para complementar os dados subjetivos. Eles representam informações mais precisas, tais como tamanho da equipe, duração do projeto, métricas etc. Essas informações devem ser obtidas junto ao gerente do projeto, pois é ele o responsável por coletar esses dados ao longo do projeto. Entretanto, devido à dificuldade de realizar essa tarefa, é importante trabalhar nas RP com quaisquer informações objetivas que estejam disponíveis.

Outras formas para coleta de dados podem ser utilizadas. Antes de dar início às reuniões de análise, os membros do projeto podem escrever, de forma resumida, os pontos fracos (ou fortes, dependendo da pauta da reunião) em uma folha em branco. Os participantes podem descrever tudo aquilo que acreditam ser importante discutir. Além disso, é importante mencionar que eles não precisam escrever seus nomes nas folhas, pois essa informação não é relevante para discussão e, possivelmente, as pessoas se sentirão mais seguras em fornecer feedback.

Análise

Antes que as reuniões de análise possam ser executadas, é importante que alguns papéis sejam definidos. Entre os participantes dessas reuniões, é possível encontrar membros do projeto, outras pessoas da organização e pessoas externas à organização. Cada uma delas exerce um papel importante para que os objetivos sejam alcançados. Os membros do projeto são responsáveis por dar informação sobre o mesmo. Outras pessoas da organização, como por exemplo um gerente de outro projeto, podem participar no sentido de agregar outras informações importantes, como política da organização, experiências passadas etc, o que pode facilitar a compreensão de algumas causas de problemas. Pessoas externas podem ser utilizadas para presidir a reunião, direcionar o debate e documentar os resultados. Para esse último papel costuma-se utilizar o termo facilitador [8].

Através de debates, sempre guiados pela figura do facilitador, é possível rastrear as causas dos sintomas. Os eventos que ocorreram ao longo do projeto são relembrados, permitindo se traçar linhas de raciocínio que culminem na chegada ao problema. Essas reuniões são de extrema importância para melhoria dos processos da organização. Além disso, as pessoas se sentem mais motivadas a trabalhar sabendo que suas queixas e elogios são levados em consideração [8].

Depois de coletar todas as informações, o facilitador deverá documentar os resultados obtidos em um relatório de andamento do projeto. Esse relatório deverá conter:

- Uma descrição do projeto

- Os principais problemas encontrados no projeto (e as causas identificadas)

- Os principais sucessos obtidos no projeto (e suas causas também) 
- Um pequeno relatório descrevendo como os participantes discutiram sobre os sucessos e fracassos do projeto.

\section{Modelos de Aplicação de Revisões de Projeto}

Embora o processo tenha sido descrito de forma genérica, ele pode ser adaptado para cada situação. Como nesse trabalho estamos considerando o desenvolvimento de software utilizando o RUP, nada mais natural que adequar o processo de aplicação das RP às características do RUP.

\section{Modelo de Aplicação I - Término de Projeto}

Nesse modelo, o final do projeto foi considerado como o término de um ciclo de desenvolvimento do software. Como o ciclo considerado é o ciclo do RUP, tem-se que os conhecimentos adquiridos só serão coletados e analisados ao término da fase de transição. Sendo assim, todos os processos são passíveis de ser avaliado (Figura 1).

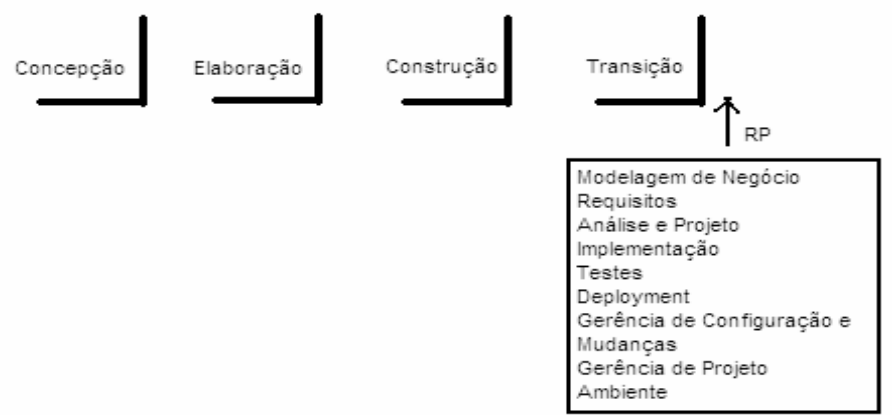

Processos a serem avaliados

Figura 1 - Modelo de aplicação das RP ao final do projeto

Modelo de Aplicação II - Término de Fase

Uma alternativa ao modelo I é distribuir a aplicação das RP ao longo do ciclo de vida. Isso pode ser feito considerando que a estratégia será aplicada ao final de marcos de controle (milestones) do projeto. Cada fase do ciclo de vida do RUP tem seus objetivos e marcos de controle bem definidos. E cada uma delas dá maior ênfase a determinados tipos de processos. A fase de construção, por exemplo, dá mais ênfase aos processos de análise e projeto, implementação e testes, diante de outros, tais como modelagem de negócio e requisitos. $\mathrm{O}$ sentido do termo ênfase nesse contexto diz respeito ao esforço e tempo despendidos. Como esses processos serão executados mais que os outros, é natural que eles sejam mais apelativos para os participantes que os outros processos. Dessa forma, espera-se que mais pontos fracos (e pontos fortes) possam ser identificados nas fases em que os processos sejam mais executados. A figura 2 descreve os momentos em que são aplicadas as RP nesse modelo e os processos a serem avaliados em cada fase. A divisão desses processos por fase foi sugerida com base na distribuição padrão dos mesmos ao longo do ciclo de vida (fig. 3). 

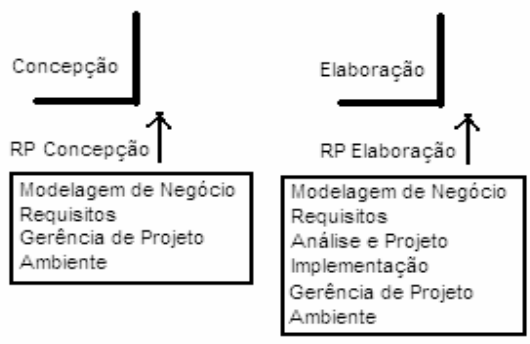

$\square$

Processos a serem avaliados
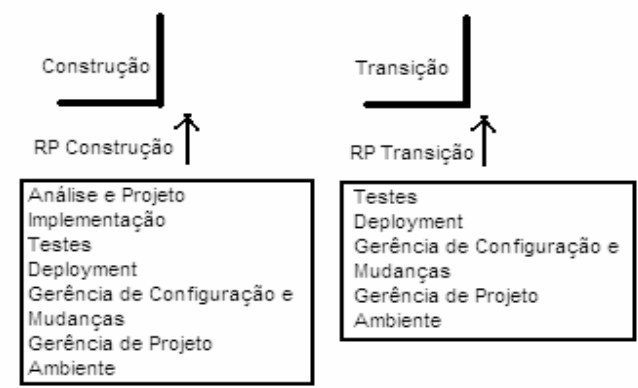

Figura 2 - Modelo de aplicação das RP ao final de cada fase

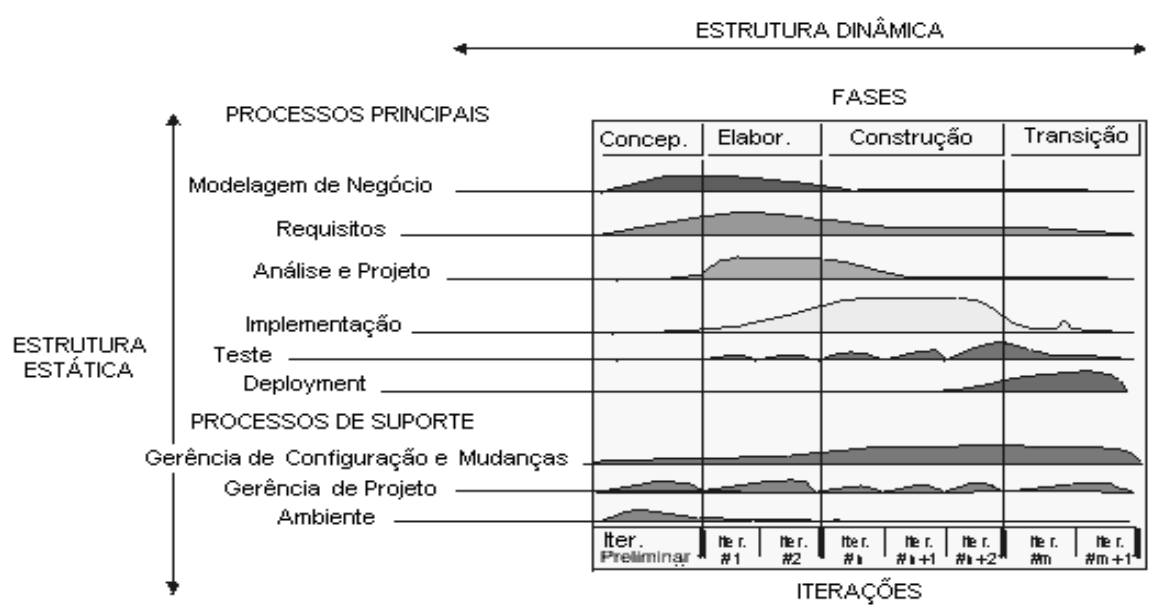

Figura 3 - Distribuição dos processos ao longo do ciclo de vida do RUP

\section{Modelo de Aplicação III - Término de Iteração}

Nesse modelo as RP são executadas ao final de cada iteração do projeto. Note que nesse caso, temos como objetivo avaliar se a iteração foi ou não bem sucedida. De acordo com as avaliações feitas nas reuniões investigativas, busca-se poder melhorar o processo para a próxima iteração. Ainda assim, pode-se levar em conta as premissas do modelo II, e considerar as iterações no contexto das fases. Dessa forma, ao final de uma iteração da fase de elaboração, por exemplo, apenas os processos mais importantes da fase serão avaliados (fig. 4).

\section{Modelo de Aplicação IV - Foco em um Processo}

Algumas organizações podem, ao invés de avaliar todos os processos do RUP, desejar focar na melhoria de um processo em particular. Essa abordagem pode ser interessante devido à grande quantidade de processos e a complexidade inerente a cada um deles. Dessa forma, uma organização pode definir, por exemplo, o processo de Testes como sendo o processo mais prioritário para melhoria, pois os sistemas desenvolvidos são críticos e erros podem causar perdas de dinheiro bastante volumosas.

Esse modelo pode ser considerado uma adaptação dos três modelos anteriores, considerando que apenas um único processo será avaliado. Ainda considerando o processo de Testes, podem-se ter as seguintes possibilidades de aplicação das RP para melhoria desse processo:

1) Ao final do projeto (Modelo I)

2) Ao final da fase de construção e transição (Modelo II) 
3) Ao final das iterações (das fases de construção e transição) (Modelo III)

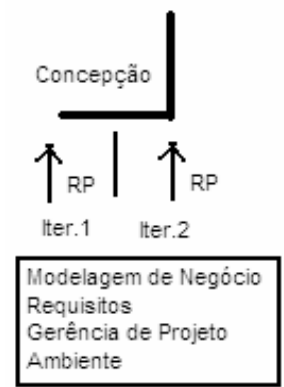

\begin{tabular}{ll} 
Ambiente & $\begin{array}{l}\text { Implementação } \\
\text { Gerência de Projeto } \\
\text { Ambiente }\end{array}$ \\
\hline
\end{tabular}

Processos a serem avaliados

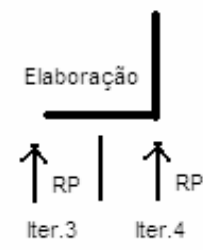

Modelagem de Negócio

Requisitos

Análise e Projeto

Gerência de Projeto $\quad$ Gerência de Configuração e

Mudanças

Gerência de Projeto

Ambiente

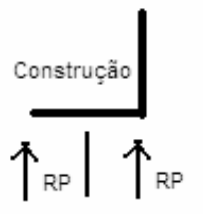

Iter.5 Iter.6

Análise e Projeto

Implementação

Testes

Deployment

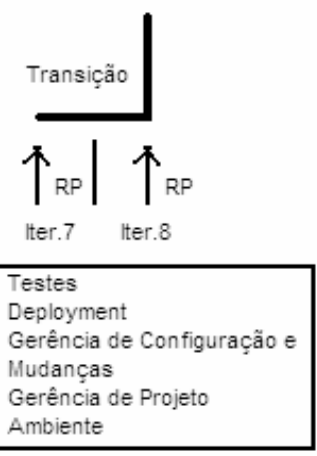

Ambiente

Figura 4 - Modelo de aplicação das RP ao final de cada iteração

A tabela 1 apresenta uma comparação entre as vantagens e desvantagens de cada modelo de aplicação apresentado:

\begin{tabular}{|c|c|c|}
\hline Aplicação das RP & Vantagens & Desvantagens \\
\hline $\begin{array}{c}\text { Modelo I } \\
\text { Término de Projeto } \\
\end{array}$ & $\begin{array}{l}\text { - } \quad \text { Não causa impacto no projeto } \\
\text { - } \quad \text { O custo é reduzido }\end{array}$ & $\begin{array}{l}\text { - Grande quantidade de processos e } \\
\text { questões a serem avaliadas num único } \\
\text { momento } \\
\text { O aprendizado sobre os pontos fracos } \\
\text { ocorridos em iterações e fases } \\
\text { anteriores pode não ser incorporado ao } \\
\text { próprio projeto } \\
\text { A distância no tempo entre os fatos e } \\
\text { eventos que afetaram o andamento do } \\
\text { projeto podem dificultar a análise }\end{array}$ \\
\hline $\begin{array}{c}\text { Modelo II } \\
\text { Término de Fase } \\
\end{array}$ & $\begin{array}{l}\text { - Foco nos processos mais relevantes } \\
\text { - Melhoria contínua do processo no } \\
\text { projeto } \\
\text { - Aprendizado sobre os pontos fortes e } \\
\text { fracos incorporado ao próprio projeto } \\
\text { - Fatos e eventos estão ainda presentes } \\
\text { na memória das pessoas }\end{array}$ & $\begin{array}{l}\text { - Impacto no projeto } \\
\text { - } \quad \text { Custo pode ser superior ao do modelo } \\
\mathrm{I}^{2}\end{array}$ \\
\hline $\begin{array}{l}\text { Modelo III } \\
\text { Término de } \\
\underline{\text { Iteração }}\end{array}$ & $\begin{array}{l}\text { - } \text { Feedback intenso } \\
\text { - } \begin{array}{l}\text { Escopo das reuniões ainda mais } \\
\text { objetivo }\end{array} \\
\end{array}$ & $\begin{array}{l}\text { - As desvantagens de aplicação desse } \\
\text { modelo são as mesmas do modelo II }\end{array}$ \\
\hline $\begin{array}{l}\text { Modelo IV } \\
\text { Foco em um } \\
\underline{\text { Processo }}\end{array}$ & $\begin{array}{l}\text { - Foco no processo mais relevante } \\
\text { - Outras vantagens são herdadas do } \\
\text { modelo que será utilizado com ele } \\
\text { (modelo I, II ou III) }\end{array}$ & $\begin{array}{l}\text { - } \quad \text { As desvantagens do modelo IV são } \\
\text { herdadas do modelo que será utilizado } \\
\text { com ele (modelo I, II ou III) }\end{array}$ \\
\hline
\end{tabular}

Tabela 1 - Comparação entre as vantagens e desvantagens de cada modelo de aplicação das RP

\section{Algumas Considerações sobre o uso de Revisões de Projeto}

Uma questão que se coloca é: quando usar cada um dos modelos de aplicação das RP? A resposta depende de uma série de variáveis. Entre elas pode-se citar o grau de inovação do

\footnotetext{
${ }^{2}$ Embora o número das RP seja maior, o tempo para execução de cada uma delas é menor, o que de certa forma pode equilibrar os custos para a sua aplicação. Além disso, os benefícios advindos dessa estratégia poderão reduzir os custos do projeto (principalmente os custos com re-trabalho e correção de defeitos principalmente), de forma a compensar os gastos com as RP.
} 
projeto, a complexidade, o tamanho (em tempo e número de pessoas), criticidade do projeto, grau de experiência da equipe no processo e nas tecnologias envolvidas, grau de maturidade da organização no processo, percepção da importância da aplicação da estratégia de aquisição de conhecimento por parte da organização, processos mais críticos, entre outras.

Como exemplo, considere um projeto pequeno (com duração de 2 meses, equipe de 4 desenvolvedores), cuja complexidade não é alta, e cuja equipe possui alguma experiência com o RUP. A utilização do modelo I (ao término do projeto) pode ser suficiente, pois o tempo do projeto não é longo e as pessoas já possuem alguma experiência no processo.

Caso a qualidade do projeto seja vital para o cliente, mais que o prazo a ser entregue, o modelo II e III pode ser considerado como uma opção interessante, visto que a realização das RP, seja no final de cada iteração, seja no final das fases, trará mais feedback para o projeto, o que possibilitará que o processo seja melhorado com mais rapidez. Conseqüentemente, a qualidade do produto será muito maior.

$\mathrm{O}$ modelo IV pode ser aplicado em organizações onde o processo e os sistemas desenvolvidos são complexos, de forma que fica difícil avaliar e buscar conhecimentos para todos os processos ao mesmo tempo. Nesse caso, pode ser interessante focar em processos mais críticos para o negócio, e aplicar as RP utilizando esse modelo.

Dessa forma, é importante observar as diferentes variáveis em jogo e determinar qual modelo mais se adeqüa à situação em questão, sempre levando em consideração os fatores mais importantes para o cliente, para o projeto, para o processo e para organização.

É importante observar também que o planejamento das RP deverá fazer parte do cronograma do projeto. Dependendo do tamanho do projeto, o tempo consumido nessas reuniões pode ser grande. Além disso, o próprio planejamento do projeto poderá ser alterado de acordo com os resultados das RP.

\section{Estratégia de Disseminação de Conhecimento}

De nada importa ter uma ótima estratégia para adquirir conhecimentos se eles não forem disseminados de forma adequada. Repositórios de conhecimentos e reuniões de análise podem ser completamente inúteis se os conhecimentos reportados não forem de simples acesso, confiáveis, bem estruturados e disseminados de forma adequada.

Segundo Peter S. Senge [11], "não existe aprendizado sem que haja ações de desenvolvimento". Como o objetivo maior da estratégia de disseminação é fazer com que as pessoas aprendam como fazer melhor, ações de desenvolvimento devem ser buscadas com base nos problemas e necessidades existentes. Essas ações de desenvolvimento são representadas basicamente pelos conhecimentos que se quer disseminar.

\section{Disseminação Planejada de Conhecimentos}

Disseminar os conhecimentos de forma planejada visa fazer com que todas as pessoas tenham uma visão uniforme sobre como executar o processo de forma a atingir um objetivo comum. Como a execução do processo está ligada à realização de um projeto, considerar-se-á a estratégia de realização de ações de desenvolvimento para disseminação de conhecimento. As ações poderão ocorrer antes do início do projeto ou ao longo do mesmo. Em geral é mais fácil que as ações sejam postas em prática antes do início do projeto, pois a equipe ainda não está comprometida com o mesmo. Entretanto, caso as RP sejam aplicadas seguindo os modelos II e III (término de fase e iteração, respectivamente) e através delas seja identificado a necessidade de realização de algumas ações, por conta de problemas vividos no projeto, planos de desenvolvimento para a equipe deverão ser elaborados. Como exemplo de ações de 
desenvolvimento, podemos citar cursos (internos ou externos), palestras, seminários, leitura de artigos, entre outras.

A estratégia de disseminação planejada proposta será aplicada através de um processo composto por três fases: planejamento, desenvolvimento de equipe e acompanhamento do aprendizado. Essas fases estão descritas em detalhes nas seções seguintes.

\section{Planejamento}

A fase de planejamento tem como objetivo planejar as ações de desenvolvimento da equipe. Essas ações poderão ser determinadas com base nas informações capturadas através das RP, tais como:

- Pontos fortes reconhecidos em outros projetos

- Pontos fracos em projetos similares

- Histórico da equipe, como por exemplo, os principais problemas enfrentados nos últimos projetos (ex.: atraso no cronograma nos últimos projetos, softwares de baixa qualidade, etc.)

Além disso, conhecimentos relativos às tecnologias que serão utilizadas no projeto também podem dar origem a ações de desenvolvimento correspondentes.

Essa fase é necessária para definir e priorizar os conhecimentos que devem ser transmitidos para a equipe do projeto. Essa tarefa cabe à equipe responsável pela melhoria do processo de software da organização. Essa equipe deve ter conhecimento sobre os pontos fortes e fracos mais importantes para a melhoria dos processos, buscando focar naquelas que irão trazer maiores benefícios para o projeto.

Para disseminar os conhecimentos relevantes através de ações de desenvolvimento, uma abordagem centrada em processo deverá ser utilizada [12]. Sendo assim, as ações devem ter sempre como objetivo a melhoria de um processo em particular. Suponha que a percepção da equipe de processo da organização seja que o processo mais crítico no momento é o de Testes. Isso se justifica pela série de pontos fracos relacionados a esse processo, e principalmente pela elevada taxa de defeitos reportados pelos clientes. Nesses pontos fracos, ações como utilização de testes de unidade e inspeções foram identificadas como possíveis soluções para esses problemas. Dessa forma, ações de desenvolvimento para ensinar a equipe a realizar inspeções podem ser solicitadas.

Manter um histórico do desempenho da equipe em projetos anteriores também pode ser importante para se tratar, com mais objetividade, os pontos fracos da mesma. Esses pontos fracos são obtidos com base nos relatórios de andamento de projetos, produzidos através das RP, e são descritos através dos pontos fracos reportados pela equipe nos últimos projetos. Esses pontos fracos também poderão determinar ações interessantes de serem propostas na fase de desenvolvimento de equipe. Isso poderá ser feito através da observação das ações a serem tomadas para remediar os problemas relacionados.

Como resultado dessa fase tem-se um plano de desenvolvimento da equipe, que deverá ser avaliado pelo gerente de projeto. Tendo sido aprovado, dá-se início a realização das ações de desenvolvimento.

\section{Desenvolvimento de Equipe}

Nessa fase, as pessoas que fazem parte da equipe do projeto se capacitam através da realização das ações de desenvolvimento propostas. Cursos poderão ser ministrados por pessoas da própria organização ou por terceiros. Possíveis instrutores poderão ser identificados durante as próprias RP. Isso pode ser feito através da identificação de pessoas experientes, que colocaram em prática os conhecimentos adquiridos. É interessante incentivar 
essas pessoas a montarem cursos e escreverem artigos ou relatórios técnicos para disseminar esses conhecimentos.

Acompanhamento do Aprendizado

Depois de realizadas as ações de desenvolvimento, é necessário atribuir algumas responsabilidades aos membros da equipe para que estes verifiquem e avaliem as ações realizadas [9]. Além disso, pontos fracos reportados em projetos anteriores, e que podem trazer riscos para o projeto em questão, também devem ser alvos de atenção constante. Nessa fase, pode ser necessária a presença de um mentor, que pode ser também uma pessoa da própria organização. Ele guiará a equipe do projeto na aplicação dos conhecimentos ensinados e avaliará sua real aplicação. Esse processo é conhecido como mentoring, e é bastante utilizado em empresas [13], principalmente quando o assunto ensinado é bastante complexo, como a adoção de uma nova metodologia ou tecnologia.

\section{Um Estudo de Caso Aplicando a Estratégia de Aquisição de Conhecimento}

Um estudo de caso foi realizado com o objetivo de aplicar a estratégia de aquisição de conhecimento em um projeto. A estratégia de disseminação não fez parte desse estudo de caso devido ao tempo limitado para elaboração e realização das ações necessárias para o projeto. Apesar disso, algumas dessas ações foram identificadas através da análise de alguns dos pontos fracos identificados, permitindo que fosse possível compreender como essas ações poderiam ser realizadas para ajudar esse projeto e outros projetos futuros.

Para elaboração do estudo de caso foi escolhido o projeto CONHECER, um projeto de pesquisa que vem sendo desenvolvido na área de engenharia de software da COPPE/UFRJ. O CONHECER tem como objetivo desenvolver o ambiente de Gerência de conhecimento CORE-KM, customizável para diferentes tipos de organização. A equipe de desenvolvimento é composta por um aluno de doutorado, três alunos de mestrado e dois alunos de graduação (além dos professores orientadores). Nesse projeto está sendo definida e implementada a infra-estrutura do ambiente, além de diversas ferramentas para apoiar atividades relacionadas à Gerência de conhecimento comuns a qualquer organização e ferramentas específicas para ambientes customizados. Uma tese de doutorado e três de mestrado estão vinculadas ao projeto. Ao aluno de doutorado cabe a responsabilidade pela gerência do projeto, enquanto que os demais alunos são desenvolvedores.

O projeto CONHECER teve seu início no final de 2001 e se estende até os dias de hoje. Outras pessoas, além das que participam atualmente, também colaboraram com o desenvolvimento do projeto, tendo os resultados de suas atividades sidos descritos através de artigos científicos e teses de mestrado. $\mathrm{O}$ atual gerente do projeto assumiu o projeto após o término da fase de concepção. Antes disso, outro aluno de doutorado desempenhava esse papel. Essa mudança ocorreu devido a alguns eventos que serão discutidos ao longo das análises feitas pelo estudo de caso. Entretanto, essa mudança não foi conseqüência das Revisões de Projeto realizadas nesse estudo de caso.

\section{Aplicação da Estratégia de Aquisição de Conhecimento}

Após a escolha deste projeto para a realização do estudo de caso foi enviado um e-mail para cada membro do projeto, descrevendo de forma resumida os objetivos deste trabalho de pesquisa e do estudo de caso, o processo de aplicação da estratégia, os papéis de cada um nesse processo, quais conhecimentos seriam buscados (pontos fracos e pontos fortes) e qual seria o uso das informações obtidas. 
Foi, então, marcada e realizada uma reunião de preparação que teve duração aproximada de 1 hora, e contou com a participação dos seis alunos participantes do projeto. Essa fase preparatória serviu para o autor (pessoa externa ao projeto e responsável pela aplicação das RP):

- descrever, com mais alguns detalhes, os objetivos do trabalho e da estratégia de aquisição de conhecimento

- ter uma visão geral do projeto

- conhecer a equipe.

Com base nas informações obtidas, tais como tempo total do projeto, fase do processo, eventos, principais fatores que afetaram o projeto e disponibilidade da equipe para poder participar das reuniões de análise, foi realizado o planejamento das RP, envolvendo o modelo de aplicação a ser utilizado e o cronograma das reuniões de análise.

Como o projeto havia acabado de concluir a fase de elaboração, optamos por aplicar o modelo II (término de fase). Além disso, a equipe de desenvolvimento sugeriu que fosse avaliada não somente a fase de elaboração, mas também a fase de concepção, embora essa já tivesse sido concluída há 4 meses atrás. Essa sugestão foi feita devido aos eventos ocorridos nessa fase, que atrasaram o projeto e que, por conseqüência, resultaram na mudança do gerente do projeto. Sendo assim, o gerente atual do projeto (que assumiu o mesmo a partir do início da fase de elaboração), não participou das atividades da fase de concepção.

Os pontos a serem discutidos foram coletados através da solicitação aos membros do projeto que escrevessem em uma folha em branco os pontos que cada um julgava importantes de serem discutidos. Em seguida, os pontos citados eram descritos em um quadro branco para que pudessem ser analisados. Além disso, antes de dar início à fase de análise dos pontos é importante que os mesmos sejam priorizados.

As reuniões de análise foram, então, divididas com base nos tipos de conhecimentos a serem adquiridos (pontos fracos ou fortes) e em relação à fase que estavam relacionados. Dois dias foram utilizados para realização das reuniões. Um dia para análise dos pontos fracos da fase de concepção e elaboração (Dia 1), e outro para análise dos pontos fortes de ambas as fases (Dia 2). Todo a equipe do projeto participou de ambas as reuniões, de forma que foi possível colher informações sobre diferentes pontos de vista. A tabela 2 apresenta o tempo dispendido em cada uma das reuniões:

\begin{tabular}{|l|c|c|}
\hline & Concepção & Elaboração \\
\hline Tempo dispendido para análise dos pontos fracos (Dia 1) & 2 horas e meia & 1 hora \\
\hline Tempo dispendido para análise dos pontos fortes (Dia 2) & 1 hora & 1 hora \\
\hline \multicolumn{2}{|c|}{ Tabela 2 - Tempo dispendido nas reuniões de análise }
\end{tabular}

Os tempos descritos na tabela 2 refletem apenas o tempo gasto nas reuniões, e não o tempo total para análise de todos os pontos levantados para discussão. Mais adiante será feita uma comparação entre o número de pontos identificados e o número de pontos que foram analisados em cada uma das reuniões. Além disso, a reunião de análise dos pontos fracos (Dia 1), para a fase de concepção, levou mais tempo que as outras principalmente porque o processo estava sendo experimentado pela primeira vez.

\section{$\underline{\text { Resultados }}$}

De acordo com a tabela 2, é possível observar que as reuniões de análise no projeto CONHECER levaram 5 horas e meia. Durante esse tempo, alguns pontos fortes e fracos foram identificados e priorizados. A tabela 3 descreve os pontos fracos e fortes priorizados e separados por fase: 


\begin{tabular}{|c|c|}
\hline \multicolumn{2}{|c|}{ Pontos Fracos } \\
\hline Concepção & Elaboração \\
\hline $\begin{array}{l}\text { 1) Ausência de liderança } \\
\text { 2) Dificuldade na alocação de responsabilidades } \\
\text { 3) Problemas de comunicação entre a equipe e o } \\
\text { gerente } \\
\text { 4) Dificuldade na compreensão geral do projeto } \\
\text { 5) Demora na especificação dos requisitos } \\
\text { 6) Ociosidade dos programadores } \\
\text { 7) Dificuldade com a nova tecnologia } \\
\text { 8) Complexidade do projeto } \\
\text { 9) Dificuldade na transferência do conhecimento }\end{array}$ & $\begin{array}{l}\text { 1) Dificuldade de integração dos subprojetos no } \\
\text { contexto do CONHECER } \\
\text { 2) Falta de experiência da equipe com conceitos e } \\
\text { modelagem OO } \\
\text { 3) Pouca disponibilidade da equipe } \\
\text { 4) Dificuldade no mapeamento OO para bancos } \\
\text { relacionais }\end{array}$ \\
\hline \multicolumn{2}{|c|}{$\begin{array}{ll} & \text { Pontos Fortes } \\
\end{array}$} \\
\hline $\begin{array}{l}\text { 1) Engajamento da equipe } \\
\text { 2) Aprendizado intenso }\end{array}$ & $\begin{array}{l}\text { 1) Infra-estrutura adequada } \\
\text { 2) Trabalho em equipe } \\
\text { 3) Aumento na compreensão do projeto }\end{array}$ \\
\hline
\end{tabular}

Tabela 3 - Pontos fracos e fortes identificados nas fases de concepção e elaboração

De todos os pontos fracos (ou fortes) identificados nas reuniões de análise, apenas alguns foram realmente analisados, pois seria preciso um número maior de reuniões para analisar todos os pontos identificados. Entretanto, os pontos fortes e fracos mais importantes foram analisados (isso porque os membros do projeto e o facilitador identificaram, antes de dar início à fase de análise, qual seria a ordem em que os pontos deveriam ser discutidos). A tabela 4 descreve a relação entre os números de pontos identificados e analisados por fase:

\begin{tabular}{|c|c|c|c|c|}
\hline \multicolumn{3}{|c|}{ Pontos Fracos } & \multicolumn{2}{c|}{ Pontos Fortes } \\
\hline & Identificados & Analisados & Identificados & Analisados \\
\hline Concepção & 9 & 2 & 2 & 2 \\
\hline Elaboração & 4 & 2 & 3 & 2 \\
\hline
\end{tabular}

Tabela 4 - Número de pontos fracos identificados e analisados nas reuniões

Através desses dados é possível ter uma idéia de como planejar as reuniões de análise. As atividades de identificação e priorização levaram em média 30 minutos em cada fase (com exceção da reunião de análise de pontos fracos para fase de concepção). Os outros 30 minutos foram para análise dos pontos. Nesse caso, cada ponto levou em média 15 minutos para ser analisado. Obviamente, esses valores variam de acordo com muitos fatores, tais como a quantidade de causas relacionadas, o grau de interesse dos membros do projeto em dar feedback, o impacto causado no projeto, entre outros. A figura 5 apresenta um diagrama de Ishikawa [14], descrevendo as causas responsáveis pelo engajamento da equipe do projeto CONHECER, identificado como o ponto forte mais importante da fase de concepção:

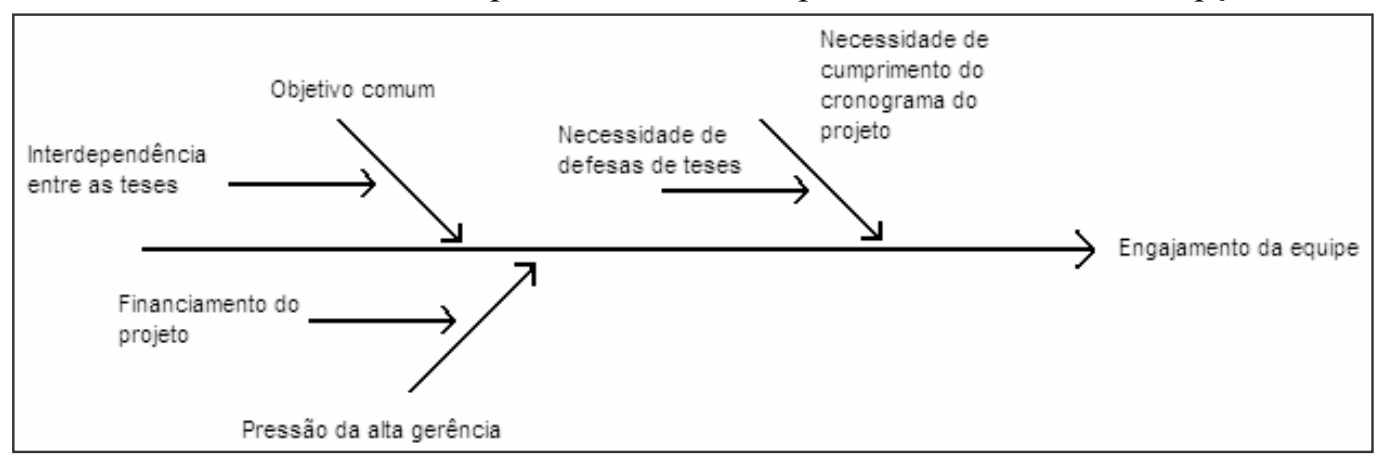

Figura 5 - Causas responsáveis pelo ponto forte "Engajamento da equipe" 
Note no diagrama da figura 5 que existem setas transversais às causas finais. Essas setas representam causas que deram origem a uma causa final. Ou seja, a "Pressão da alta gerência" era necessária porque o "Financiamento do projeto" estava condicionado aos resultados obtidos com o projeto. Esse ponto forte, em particular, levou mais tempo que os outros para ser analisado, pois possuía muitas causas relacionadas.

É interessante também observar a categorização dos pontos segundo os processos do RUP. A tabela 5 traz os pontos fracos da fase de concepção categorizados:

\begin{tabular}{|l|l|}
\hline \multicolumn{1}{|c|}{ Pontos Fracos } \\
\hline Requisitos & \multicolumn{1}{c|}{ Concepção } \\
\hline Análise e Projeto & 5) Demora na especificação dos requisitos \\
\hline Implementação & 7) Dificuldade com a nova tecnologia \\
\hline Gerência de projeto & 7) Dificuldade com a nova tecnologia \\
& 1) Ausência de liderança \\
& 2) Dificuldade na alocação de responsabilidades \\
& 3) Problemas de comunicação entre a equipe e o gerente \\
& 6) Ociosidade dos programadores \\
\hline $\begin{array}{l}\text { Pontos fracos não relacionados } \\
\text { aos processos RUP }\end{array}$ & 9) Dificuldade na transferência do conhecimento \\
\hline
\end{tabular}

Tabela 5 - Distribuição de pontos fracos na fase de concepção segundo os processos do RUP

Observando os pontos fracos da fase de concepção e os pontos fortes da fase de elaboração, é possível perceber que uma simples ação pode mudar o rumo de um projeto. $\mathrm{O}$ processo de gerência de projetos, que foi o mais deficitário da fase de concepção, sequer foi mencionado como possuindo algum ponto fraco na fase seguinte. Pelo contrário, o ponto forte "Trabalho em equipe" foi citado como um grande diferencial obtido na fase de elaboração. Vale a pena lembrar que a ação para essa melhoria (mudança do gerente do projeto) foi tomada antes da aplicação das RP, por conta da interferência direta dos professores orientadores. Sendo assim, é interessante observar que ações como as que foram tomadas poderiam ser buscadas com base nos resultados das reuniões de análise feitas nesse estudo de caso. Além disso, se essas reuniões tivessem acontecido antes do final da fase de concepção (aplicando as RP ao final de cada iteração, por exemplo), possivelmente o problema teria sido identificado antes e ações para contorná-lo poderiam ter sido tomadas mais cedo.

Ao categorizar os pontos identificados, é possível perceber que alguns pontos não estavam necessariamente relacionados ao RUP. Esses pontos correspondem normalmente a dificuldades inerentes ao projeto e/ou características da equipe de desenvolvimento. Sendo assim, decidiu-se por separá-los para efeito de categorização.

Além da análise dos pontos, conseqüências e ações foram debatidas para cada ponto analisado. A tabela 6 apresenta as conseqüências e ações identificadas para um dos pontos fracos da fase de elaboração:

\begin{tabular}{|l|l|}
\hline \multicolumn{1}{|c|}{ Ponto fraco: Falta de experiência da equipe com conceitos e modelagem OO } \\
\hline \multicolumn{1}{|c|}{ Conseqüências } & \multicolumn{1}{c|}{ Ações } \\
\hline -Re-trabalho & -Treinamento (Cursos de modelagem OO) \\
-Dificuldade no mapeamento OO para bancos relacionais & $\begin{array}{l}\text {-Suporte de especialistas em OO } \\
\text {-Leitura de artigos técnicos }\end{array}$ \\
\hline
\end{tabular}

Tabela 6 - Conseqüências e ações para um ponto fraco

Embora a estratégia de disseminação não tenha sido colocada em prática, as ações debatidas durante a análise de alguns pontos (como o apresentado na tabela 6) poderiam fazer parte de um plano de desenvolvimento para a equipe do projeto CONHECER e para outros projetos OO. Dessa forma, seria possível minimizar os riscos de projetos futuros através da disseminação do conhecimento já adquirido nesse projeto. 
Receptividade e Participação dos Membros do Projeto

"Discutir e compreender as causas dos problemas evita que nos sintamos culpados por alguma coisa de ruim no projeto."

"Reuniões como essa permitem que possamos saber a opinião de cada pessoa sobre o andamento do projeto e, principalmente, de que forma poderemos contribuir para o sucesso do projeto."

Esses são alguns dos comentários dos membros do projeto. Ao realizar essas reuniões de análise fica claro o papel social desempenhado pelas mesmas. É muito comum uma pessoa comentar com outras suas preocupações sobre o rumo do projeto, embora isso normalmente seja feito de forma particular. O que as reuniões de análise buscam é proporcionar um ambiente em que as pessoas se sintam motivadas e seguras a relatar seus pontos de vista, de forma a poder eliminar problemas atuais e riscos futuros.

A participação dos membros do projeto CONHECER foi muito boa. Todos os membros participaram das reuniões e todos eles deram bastante feedback sobre o projeto e sobre as reuniões de análise.

\section{Conclusões e Perspectivas Futuras}

Através do estudo de caso realizado junto ao projeto CONHECER foi possível experimentar a estratégia de aquisição de conhecimento e entender como a estratégia de disseminação de conhecimento poderia ser utilizada com base nos resultados do experimento.

As reuniões de análise se mostraram muito úteis na aquisição dos conhecimentos de interesse, ou seja, os pontos fortes e fracos presentes no projeto. Foi possível também avaliar o modelo II de aplicação das RP (término de fase) para as fases de concepção e elaboração. Além disso, as reuniões também tiveram uma boa receptividade por parte dos participantes do projeto.

O estudo de caso também possibilitou avaliar o tempo gasto nas reuniões de análise. Através desses resultados é possível estimar tempo e custo para aplicar a estratégia proposta e avaliar o impacto causado pelas mesmas no planejamento de projetos.

Com base nas ações de melhoria discutidas foi possível também entender como a estratégia de disseminação de conhecimento poderia ser utilizada para contornar os pontos fracos identificados, como aquelas apresentadas na tabela 6 .

Através das estratégias propostas e dos resultados obtidos com o estudo de caso, espera-se que esse trabalho possa contribuir para a melhoria de projetos que usem o RUP como processo de desenvolvimento. Essa melhoria deverá estar fundamentada na criação de uma cultura organizacional de compartilhamento de conhecimentos, onde as estratégias de aquisição e disseminação de conhecimento apóiem os projetos em andamento.

Embora tenha sido realizado um estudo de caso aplicando a estratégia de aquisição de conhecimento em um projeto, é preciso que outros estudos sejam realizados para avaliar a aplicabilidade dessa estratégia e também da estratégia de disseminação de conhecimento.

Sendo assim, diversos estudos podem ser realizados com base nesse trabalho, seja através de sua continuidade, seja através de algumas adaptações:

- O estudo de caso realizado nessa teve levou em consideração apenas um projeto; além disso, um projeto de pesquisa possui características diferentes de um projeto realizado por uma empresa. Sendo assim, seria muito interessante que as estratégias propostas pudessem ser realizadas em outros projetos, de preferência em empresas.

- Apenas o modelo II (término de fase) foi experimentado no estudo de caso. Na literatura é possível encontrar estudos onde o modelo I (término de projeto) foi utilizado $[8,14]$. 
Novos estudos poderiam ser realizados aplicando os outros modelos propostos (III e IV) . Através desses estudos pode ser possível ter mais parâmetros comparativos sobre as vantagens e desvantagens de cada modelo.

- Adaptações às estratégias poderiam ser propostas para efeito de aplicação em outros processos de desenvolvimento. Os modelos de aplicação propostos para o RUP também se aplicam em outros processos iterativos, como é o caso do XP [15]. Esses modelos poderiam ser avaliados e outros novos poderiam ser propostos.

\section{Referências}

1. Kroll, P., 2001, "The RUP: An Industry-wide Platform for Best Practices", Online: http://www.therationaledge.com/content/dec 01/f TheRUP_pk.html.

2. Jacobson, I., Booch, G., Rumbaugh, J., 1998, The Unified Software Development Process, Reading, Massachusetts, Addison-Wesley.

3. Davenport, T.H. e Prusak, L., 1998, Working Knowledge: How Organizations Manage What They Know, Harvard College Business School Press, Boston.

4. Nonaka, I., Takeuchi, H., 1995, The Knowledge Creation Company: How Japanese Companies Create the Dynamics of Innovation, Oxford University Press, New York.

5. ISO/IEC 12207, 2001, Information Technology - Amendment to ISO/IEC 12207, Montreal: ISO/IEC JTC1 SC7.

6. Rus, I., Lindvall, M., 2002, "Knowledge Management in Software Engineering”, IEEE Software, Maio/Junho, pp. 26-38.

7. Basili, V.R., Caldieira, G., Rombach, D., 1994, “The Experience Factory”, Encyclopedia of Software Engineering, Volume 1, pp. 469-476.

8. Birk, A., Dingsøyr, T. Stalhane, T., 2002, "Postmortem: Never Leave a Project without It", IEEE Software, Maio/Junho, pp. 43-45.

9. Collier, B., DeMarco, T., Fearey, P., "A Defined Process For Project Post Mortem Review", IEEE Software, Júlio/Agosto, pp. 65-72.

10. Nolan, A. J., 1999,“Learning from Success”, IEEE Software, Janeiro/Fevereiro, pp. 97105.

11. Senge, P. M., The Fifth Discipline: The Art and Practice of the Learning Organization, New York: Doubleday.

12. Holz, H., Könnecker, A., Maurer, F., 2001, “Task-Specific Knowledge Management in a Process-Centred SEE”, LSO 2001, LNCS 2176, pp. 163-177.

13. Apostolou, D., Mentzas, G., 1998, "Managing Corporate Knowledge: A Comparative Analysis of Experiences in Consulting Firms", Second International Conference on Practical Aspects of Knowledge Management, Basel, Suíça.

14. Dingsøyr, T., Moe, N. B., Nytrø, Ø., 2001, “Augmenting Experience Reports with Lightweight Postmortem Reviews", $3{ }^{\text {rd }}$ International Conference Product Focused Software Process Improvement (Profes 01), Lecture Notes in Computer Science, vol. 2188, SpringerVerlag, Berlin, pp. 167-181.

15. Beck, K., 2000, Extreme Programming Explained, Addison-Wesley. 